\title{
Alcohol Sponsorship and New Zealand Regional Rugby Unions: Crisis Point or Business as Usual?
}

\author{
Sarah Gee ${ }^{1} \cdot$ Rachel Batty ${ }^{2} \cdot$ Patti Millar $^{1}$ \\ Received: 9 July 2020 / Accepted: 7 October 2020 / Published online: 15 October 2020 \\ (C) Springer Nature Switzerland AG 2020
}

\begin{abstract}
Alcohol sponsorship of sport in New Zealand, especially rugby, has a long history, but in recent times government-resourced reviews together with public health agencies, activists, and academics have proposed a ban of alcohol sponsorship of sport to help reduce alcoholrelated harm. Responses to a proposed ban from a number of diverse sectors, including the alcohol industry and sport organizations, have ranged from ambiguous to resistant. Yet, the conditions for implementing a ban are poorly understood and there has been no change to state-regulated sponsorship policy to date. These widely publicized debates serve as a hotbed for discussions with provincial rugby union managers to consider the economic risks as well as the social connections between rugby clubs and cultural and civic life. In this paper, we address important new questions that query how the alcohol sponsorship debate plays out at a micro-level and the extent to which regional rugby unions may constitute a special case in terms of resistance to and the potential effects of regulation. The discussion expands the debate by drawing attention to the perceived positive effects of alcohol sponsorship as an enabler for addressing other social issues at a micro-level.
\end{abstract}

Keywords Regional sport organizations · Sport sponsorship · Alcohol · Regulation · Gender

\section{Introduction and National Alcohol Sponsorship Policy Context}

"...corporations condition leisure forms and practice. The mechanisms by which this is achieved extend well beyond designing and marketing leisure commodities

Sarah Gee

Sarah.Gee@uwindsor.ca

1 Department of Kinesiology, University of Windsor, Windsor, Ontario, Canada

2 School of Sport, Exercise, and Nutrition, Massey University, Albany, New Zealand 
and services. Advertising, sponsorship and lobbying state officials and political parties are all part of the commercial leisure panoply." (Rojek 2010, p.35)

Sport and alcohol are two highly commodified and globally popular leisure pursuits, although their relationship is paradoxical. Rightly or wrongly, alcohol is widely regarded as an everyday product (cf. Babor et al. 2010; Wenner and Jackson 2009), as a leisure commodity (Rojek 2010) with links to forms of leisure such as home brewing (Duarte Alonso et al. 2018), beer appreciation (Thurnell-Read 2016), and beer tourism (Bujdosó and Szücs 2012), and advertising often portrays alcohol consumption as a normal, requisite leisure practice (e.g., Rowe and Gilmour 2009). From a public health perspective alcohol is an unhealthy product, and consuming harmful quantities of alcohol can have detrimental health and social consequences for the drinker, the people around the drinker, and society at large (World Health Organization 2014). In his book, The Labour of Leisure, Chris Rojek (2010) argues that to evade criticism about the physical and social risks of the products they produce, alcohol corporations associate their product with the leisure and recreation field, including sport; a form of leisure that is frequently linked to values related to fitness, healthy living, an active lifestyle, and youth. In many Western nations, the alcohol industry has indoctrinated sport through sponsorship.

Alcohol sponsorship of sport in New Zealand has a long, convoluted history that includes the sponsorship of teams (at the club, provincial and national levels) and events (All Blacks matches, Rugby World Cups, and provincial competitions). Financial, contra, and in-kind support from the alcohol industry is essential for many New Zealand sports clubs (PS Services 2010). Moreover, the links between New Zealand's national sport of rugby and alcohol brands are extensive, engrained, and entangled (Gee and Jackson 2010, 2012; Gee et al. 2016; Gee et al. 2018), which presents some fundamental complexities when envisioning one without the other.

Since 2010, the New Zealand government has commissioned two independent reviews related to alcohol sponsorship. The first was conducted in 2010 by the New Zealand Law Commission. At the time, the Law Commission was charged with the task to provide the government with "a revised policy framework covering the principles that should regulate the sale, supply and consumption of liquor in New Zealand having regard to present and future social conditions and needs" (Law Commission 2010, p. iv). The Law Commission's process for this review included synthesizing research, consultations with health agencies and social welfare alliances, and an open call for submissions from the public and other organizations. ${ }^{1}$ The 511-page, 24 chapter final report, entitled Alcohol in Our Lives: Curbing the Harm, is all-encompassing and examines a range of factors concerned with: limiting alcohol-related harm (e.g., monitoring, enforcement, education), controlling supply of alcohol (e.g., licencing, purchase age), regulating its availability (e.g., proximity and nature of outlets, times of sale), and reducing the demand (e.g., price, advertising and sponsorship). Of note, Chapter 19 of the report specifically details current (at the time) and prospective manifestations and regulations of alcohol advertising, sponsorship, and promotion, including the prominent marketing of alcohol through sport. The arguments presented

\footnotetext{
${ }^{1}$ There were a total of 2939 written submissions that responded to the Law Commission's Issues Paper, entitled Alcohol in our Lives, and 50 public meetings held in 16 different locations across New Zealand (Law Commission 2010).
} 
in the chapter acknowledge that some promotional elements such as advertising have formalized guidelines through the Code for Liquor Advertising developed by the Advertising Standards Authority, yet other elements such as sponsorship are excluded from these Codes. However, the gathering of all research results, submissions, and consultations provided a compelling argument about the effects of alcohol promotions on the health of New Zealanders that one section of the Chapter's recommendations introduces a staged-approach to ban alcohol-related sponsorship of cultural and sports events or activities over a five year period. This proposition further upholds that: "if the funds that the alcohol industry pours into the community are to come to an end, it is critical that there is a way to replace the contribution of such sponsorship to sporting, cultural and community programmes" (Law Commission 2010, p.360). This indicates some level of awareness about significant financial implications for many community organizations that depend on monies from alcohol companies, including sport, and a need to fill that gap to ensure continued provision of these community-based activities.

In the months following the release of the Law Commission's report, Sport New Zealand (at that time known as SPARC; a Crown entity responsible for governing sport and recreation in New Zealand) published the results of their own commissioned, scoping study. This study sought to examine evidence and insights into the nature of the relationship between alcohol and sport with the overall purpose to: enable Sport New Zealand to make an informed contribution on the government's reviews on alcohol regulations, and allow Sport New Zealand to lead the sport sector through any regulatory reform (PS Services 2010). While the report discusses a number of topics about the sport-alcohol relationship, one section relevant to the context of this paper specifically states that the New Zealand Rugby Union (NZRU; the national sports organization for rugby) considered the alcohol industry as a vital source of funding. The report further claims that according to the NZRU, any loss of funding revenue would curtail activities at all levels of rugby, with critical effects on:

- 'Increased club fees or reductions in activities funded by sponsors (e.g., equipment, apparel, safety gear), which may see those with less money having to drop out of the sport;

- Elimination of branding opportunities for sponsors (such as touch-line flags, goalpost pads) meaning clubs will have to find the money to buy these items from elsewhere;

- A risk that clubrooms may not be able to cover basic operating expenses and have to close, with a consequence that teams may make local pubs their home-base for after-game functions and socialization, which will exclude the family-friendly environments offered by clubs;

- Less ability to fund people in development roles, who are currently working with clubs and communities to strengthen them and support the large volunteer base that exists;

- In the professional arm of the sport, less money to pay players (meaning more will head offshore), to promote matches and spend on match experiences, which risks a downward spiral in the quality of this part of the game" (PS Services 2010, p.26).

Concurrently, Cody and Jackson (2016) conducted a study with several key stakeholders in the New Zealand sports and alcohol industries to investigate their 
perceptions on the potential consequences of additional regulation on alcohol sponsorship of sport from the Law Commission's report. Similar to the findings of Sport New Zealand's report, a majority of their participants noted a strong dependence on alcohol funding, linking it with their means of survival. In New Zealand, alcohol sponsorship is plentiful and, therefore, convenient (from a sponsorship recruitment stance), and without any guarantee of alternative funding from the government there is resounding agreement from these stakeholders that a ban is risky (Cody and Jackson 2016). The authors conclude that while alcohol sponsorship is the lifeblood of many sport organizations, "sport teams face the challenge of trying to balance the need for sponsorship with the social pressures to develop a responsible drinking culture not only to maintain a positive social image, but also for performance" (Cody and Jackson 2016, p.389). Overall, Cody and Jackson (2016) provide a well-evidenced argument that characterizes alcohol sponsorship of sport as a contested terrain with different interest groups and individuals having diverse perspectives about its nature and meaning to sport in New Zealand.

In 2012, the New Zealand government passed the Sale and Supply of Alcohol Act in response to some of the recommendations made by the 2010 Law Commission report. Some of the key points in the act include modifications in: trading hours for on- and off-licence premises, where alcohol can be sold, and how liquor licences are issued. However, there were no changes to alcohol advertising and sponsorship of sport as part of this Act.

The second government commissioned review was conducted in 2014 by a Ministerial Forum on Alcohol Advertising and Sponsorship. Similar to the Law Commission's approach, the Forum considered published research since the 2010 Law Commission report, as well as submissions and presentations from community members, individuals, and organizations from a range of sectors (e.g., public health programing, sports and event sponsorship and management, and alcohol industry and media representatives). ${ }^{2}$ In the report that describes the Forum's analysis of the submissions, the topic of sport featured most prominently in the alcohol sponsorship section. The Forum's summary of the submissions reported that $42 \%$ of submissions that supported maintaining the status quo of current regulations were from sporting bodies, and included an entire section on alcohol sponsorship of sport (see Section 3.3.1.1 Value to Sports, Ministry of Health 2014a). In this section, key concerns that focus on community-level sport include: a ban of alcohol sponsorship would have the largest impact on lower-tier, grassroots sports clubs citing an undermining of economic viability; offsetting loss of sponsorship monies from the alcohol industry would result in increased participation and membership costs; and ending alcohol sponsorship would impact the role of sport in developing and promoting the social capital of communities and, consequently, effect overall wellbeing (Ministry of Health 2014a, pp. 60-62). In the summary of submissions document, health-related organizations supported increased restrictions on alcohol sponsorship of sport, including a complete ban, while sport-related organizations were in favour of maintaining the current selfregulatory framework, which allows for alcohol sponsorship (e.g., Sport New

\footnotetext{
${ }^{2}$ A total of 242 submissions were received. One hundred and twenty-two (122) submissions were received from organizations and 120 were from individuals. Of the 122 submissions from organizations, 27 of them were submitted by sport organizations (Ministry of Health 2014a).
} 
Zealand's submission incorporated data from their commissioned research report in 2010; PS Services 2010). These polarized opinions are somewhat surprising, given that the shared purpose of many of these organizations is to increase the health of all New Zealanders. The Forum's final report proposed 14 recommendations to reduce the exposure of youth to alcohol advertising and sponsorship. With specific reference to sport, Recommendations One and Two stated: "Ban alcohol sponsorship of all streamed and broadcast sport" and "Ban alcohol sponsorship of sports [long term]", respectively (Ministry of Health 2014b, p.3). In light of the Forum's recommendations and similar proposals from the Law Commission, debates about alcohol sponsorship of sport heightened across New Zealand. A year after the release of the Forum's report, one particular news article highlighted the Government's lack of movement on any of the recommendations (Anthony 2016). In the article, the then Chief Executive of New Zealand Rugby, Steve Tew, claimed:

It would be an awful lot harder for our provincial unions and the local rugby clubs, as it would be for other community organisations, that are still reliant on the support they get from local publicans, local restaurants, the two big breweries and increasingly the large number of boutique craft breweries. (Anthony 2016)

Despite these publicly-funded reviews, there has been no change to state regulation or policy to date, and given the lobbying power of the alcohol industry there is little reason to be optimistic (Skegg 2019).

Framed by this context, the purpose of this study was to examine the perceptions of and challenges for regional rugby unions to navigate a potential ban of alcohol sponsorship of sport. This purpose was intentionally broad in nature to capture a range of insights about the rugby-alcohol sponsorship landscape and any anticipated consequences arising from proposed threats to it. Building on previous studies that focus on the relationship between alcohol sponsorship and sport in New Zealand (Cody and Jackson 2016; Gee 2013), this study addresses important new questions that query how the alcohol sponsorship debate plays out at a micro-level and the extent to which regional rugby unions may constitute a special case in terms of resistance to and the potential effects of regulation. Significantly, the paper expands the debate by drawing attention to the perceived positive effects of alcohol sponsorship as an enabler for addressing other social issues at a micro-level. By focusing on a culturally-ingrained, and arguably 'naturalized', relationship between sport and alcohol, this study informs debates on identity construction in sporting cultures.

\section{Review of Literature}

\subsection{Sport Organizations as Sites for Community Development}

Regional and community sport organizations function as social pillars in our communities as they serve as the central providers of sport and recreation and as social hubs and meeting places for children, parents, athletes, spectators, and community members more broadly (Robertson et al. 2018; Spaaij 2013; Trussell 2020; Waardenburg 2016). In this way, sport offers a central gathering place for participants and their families with 
benefits that far exceed those associated with physical participation in sport (Edwards 2015; Eime et al. 2013; Mair 2009; Tonts 2005). Interactions in and around sport can create and sustain meaningful personal, social, and cultural experiences that can build community connectivity (Edwards 2015; Spaaij 2013), influence community relationships (Sharpe 2006; Trussell 2020), enhance civic engagement (Donovan et al. 2004; Kay and Bradbury 2009; Nichols et al. 2014), and foster a sense of community (Warner et al. 2012; Wendel et al. 2009). Edwards (2015) advances that "the community level [in particular] may provide the best context for this connectivity to occur...with sport programs potentially providing individuals with greater access to social support than involvement in other types of community voluntary organizations" (p. 11). Notably, others have found that the social networks developed through sport provide greater social value than those developed through non-sport community organizations (Nicholson et al. 2013). This is perhaps the result of simply providing access to a social network framed around similar values and interests, and the added social support that that introduces (Doherty et al. 2014; Jones et al. 2018; Warner et al. 2013).

Sport's potential as an instrument for community development has resulted in several national sport mandates built on the notion of 'sport as a social good', where governing agencies view sport as a means to achieve broader social outcomes (e.g., reducing crime and youth delinquency, enhancing civic and political engagement, fostering social cohesion; Sabbe et al. 2020; Sam 2009; Spaaij 2013). This popular perception is reflected in descriptions of sport as the "glue holding communities together" or the "lifeblood of the community" (Spaaij 2013, p. 110) that contribute to bringing communities (and nations) together. Nicholson et al. (2013) suggest that those who become involved in sport for instrumental reasons, such as fun or fitness, are likely to experience additional benefits once they are integrated into the social network created by and around the sport organization. Further, Donovan et al. (2004) found that, in New Zealand, membership in sports was associated with higher levels of political and civic engagement, where members of sport clubs (including participants, coaches, volunteers, officials, etc.) were more likely to engage in discussions around current political issues, vote in elections, and advocate for social issues. Sport is an important part of community life and has the potential to build shared understanding and social change through its collective nature (Trussell 2020).

Collective community activities have witnessed a decline in recent years as the ways in which individuals interact with one another have shifted from a neighbourhooddriven community towards a small network of close contacts (Mair 2009; Warner et al. 2013). Sport may be one of the few public structures where community members experience intensive interaction in their leisure time (Edwards 2015) and, as such, "represents a social institution that offers a collective social experience" (Warner et al. 2013 , p. 350). In fact, sport may be particularly well positioned to create, enhance, and reinforce community at the local level, resulting in a greater sense of belonging and social support among members, prolonged participation, and improved health and wellness outcomes (Tonts 2005; Warner et al. 2012, 2013). However, Warner et al. (2012) caution that sport does not automatically create a sense of community and afford the benefits of a social network to participants; rather, it manifests as the result of several individual and organizational factors. Relatedly, previous research has pointed to the capacity challenges that sport organizations face in their efforts to offer quality programming, effective operations, and a connection in the community (e.g., Doherty 
and Cuskelly 2020; Doherty et al. 2014; Sharpe 2006; Wicker and Breuer 2014). In the New Zealand context, sport clubs face significant financial constraints in terms of obtaining sufficient income and maintaining financial viability; this is further exacerbated by the fact that grassroots sport clubs in New Zealand receive little (if any) government funding and therefore need to be extra cognizant of their financial resources (Cordery et al. 2013). The funds acquired through alcohol sponsorships serve as critical financial resources for local community sports clubs through to the national level (Law Commission 2010; Ministry of Health 2014a, b).

\subsection{Alcohol Sponsorship and Sport}

The sport and alcohol relationship is complex. On the one hand, the link between them has been characterized by scholars within the sociology of sport, sport management, and policy studies as a "nexus" (Palmer 2011), a "dyad" (McDaniel and Mason 1999), a "partnership" (Munro 2000), and "a global cocktail" (Gee 2020). On the other hand, it has been critiqued as "problematic" (Jones 2010), culturally hypocritical (Johnson 1988), a "cultural irony" (Wenner 1991), and a "contested terrain" (Cody and Jackson 2016). Indeed, alcohol is no ordinary commodity (Babor et al. 2010), and consuming harmful quantities of alcohol can have detrimental health and social consequences for the drinker, the people around the drinker, and society at large (World Health Organization 2014). Yet, sport plays an important role in normalizing alcohol because it is widely regarded as a healthy activity; it is a globally popular, highly visible, and influential part of society; and, it attracts large audiences and participants.

Many community and regional sport organizations depend on support from sponsorships (Batty et al. 2016; Misener and Doherty 2014). Meenaghan (1983, p. 9) defines sponsorship as "the provision of assistance either financial or in-kind to an activity by a commercial organization for the purpose of achieving commercial objectives." Alcohol brands, breweries, and establishments (pubs) have been long-time supporters of sport (Collins and Vamplew 2002). However, some researchers would suggest that in recent times alcohol sponsorship has dominated sport (Jones 2010), to the extent that sport has become a key vehicle through which alcohol is consumed, promoted, and glorified. As Crompton (2014, p. 426) notes:

Sponsorship and advertising by beer companies promotes the image that beer is not very different from soft drinks, and its negative consequences such as traffic deaths, domestic violence, physical deterioration from cirrhosis, hypertension and stroke, and pregnancy risks are ignored. Alcohol sponsorship aspires to create positive brand image transfer associated with sport teams and athletes: vitality, fitness, fun, health, endurance, speed and strength. [...] The concern is that beer companies' promotions connote it is natural for this intoxicating drug to be consumed while watching, or after participating in, a sporting activity.

Several sports fields throughout New Zealand are cladded with alcohol logos and many clubrooms serve alcohol to provide an income stream, subsidize memberships, and are common meeting halls for communities. But there is a dark side underscored by quantitative research that suggests that people involved in community sports clubs 
report higher levels of harmful alcohol consumption than among community members generally (O'Brien et al. 2007), and sportspeople who receive alcohol sponsorship in the form of free or discounted alcohol score higher on risky drinking behaviours (O'Brien and Kypri 2008). While quantifying alcohol sponsorship of sport is difficult given the various methods that sponsorship manifests itself (e.g., pourage rights, discounted or free product, alcohol-branded sports equipment, cash), debates on the inappropriateness of alcohol sponsorship of sport highlight public health concerns related to consuming and promoting alcohol associated with an activity that serves to accentuate fundamental social attributes, facilitate civic engagement, and generate health benefits.

It is undeniable that beer and sport are key signifiers of masculine identity. The sport of rugby has a long association with drinking culture, hegemonic masculinity, and alcohol sponsorship. Historically, rugby was an all-male preserve (Dunning 1986; Nauright and Chandler 1996), an exclusive male-dominated and male-defined space where men confirmed their masculinity through physical combat, the consumption of alcohol and, in some cases, the singing of songs that sexualized and objectified women. Even today, participating in rugby and its associated culture continue to be some of the surest ways to perform and conform to a dominant (or hegemonic) version of masculinity for New Zealand boys and men (Pringle and Markula 2005). Arguably, sport and beer represent two of the "final frontiers" for the expression and confirmation of a dominant masculine ideology (Gee and Jackson 2017). Much of the research on alcohol promotion and, to some extent, sponsorship of sport leans heavily towards using a hegemonic masculinity approach (see Gee and Jackson 2012; Jackson 2014; Wenner and Jackson 2009). These narratives perpetuate strong connections between sport and men, beer and men, and strengthen the normalized practice of marketing beer brands through men's sport. Beer companies are longstanding supporters of men's rugby, for example, Heineken's current 25-year sponsorship of the Rugby World Cup and Steinlager's current 30-year sponsorship of the New Zealand All Blacks (see Gee 2013; Gee et al. 2018). The stitching together of beer sponsorship and men's rugby in New Zealand is entrenched with socio-historical prominence and entangled in political-economic agendas with wide-reaching implications for cultural identity and hegemonic masculinity.

\section{Methodology}

Qualitative research can aid in understanding the natural setting and how sport is experienced, in addition to placing community and cultural influences in context (Shaw and Hoeber 2016). In applying this notion, we adopted an exploratory qualitative research approach to gain an in depth understanding of regional sport organization sponsorship and the meaning that individuals with decision-making capabilities for organizations ascribe to social issues (Creswell 2009; Merriam 2009). A qualitative case study approach supported perceptions of patterns of behaviour due to social convention (Edwards and Skinner 2009), while also allowing for recognition of any differing regional perspectives and influences on regional stakeholder alignments (Braun and Clarke 2006; Creswell 2009; Eisenhardt and Graebner 2007; Yin 2012). 


\subsection{Data Set Identification and Rationale}

New Zealand Rugby, the national sport organization, governs the sport at the national level, and also oversees 26 regional rugby organizations that are responsible for the administration of strategic rugby initiatives at the regional level, as well as the facilitation of grassroots rugby, from youth to adult representative grades. Geographical regions in New Zealand are unique in their size, population, and demographics. In this regard, the funds and resources received, the organizational and management structure of each regional rugby union, the number and diversity of teams, and the quantity and scope of potential sponsors make for exceptional circumstances for individual regional rugby organizations. In noting the differences between the geographic regions and regional rugby unions, the country was segmented into six geographic areas. These areas were identified based on the urban, suburban, and rural regional rugby organizations that, collectively, feed into the same provincial team (i.e., at the elite performance level). The distinction between urban, suburban, and rural organizations was based on a combination of population numbers and density, along with geographic area. Each of the six geographic areas were identified as a research phase. The first phase was based on one of the larger geographic areas located towards the centre of the country, which forms the focus of this paper. This initial research phase allowed for a balance of rural (two), suburban (two), and urban (two) regional rugby organizations. Furthermore, all six regional rugby organizations had an alcohol brand sponsor. This context offered a comprehensive starting point for a broader, national research project and formed a purposive sampling approach to the research (Palinkas et al. 2015).

This research utilized the sport of rugby in New Zealand as a case study to facilitate discussion about a public health agenda influence on regional sport sponsorship. Justification for this decision was based on five key credentials. First, rugby is a site of historical, cultural and national significance in New Zealand, with many regarding it as the national sport (Grainger et al. 2012; Scherer et al. 2008). Second, many New Zealanders participate in rugby, with player registrations exceeding 157,000 in 2018 (New Zealand Rugby 2019). Non-player involvement in the sport is also widespread when considering coaches, sponsorship, support networks, medical practitioners, commercial sporting equipment manufacturers, and club administrative staff (New Zealand Rugby 2019). Third, the social magnitude and popularity of the sport are recognized through the extensive organization of rugby in New Zealand, with a network of 26 regional rugby unions located across the country (New Zealand Rugby 2019). Fourth, sponsorship of rugby is unparalleled in New Zealand, largely due to widespread media coverage of national and international teams and collective national interest (Carter et al. 2013). Lastly, rugby has a long history with alcohol sponsorship (Gee 2013; Gee et al. 2018) and other unhealthy food and beverages (Carter et al. 2013). Taken together, rugby is a strategic and symbolic sport for analysis.

\subsection{Data Collection}

Individuals with managerial knowledge and experiences of the sponsorship arrangements for a regional rugby union offer incisive views that "establish, conceptually/theoretically, points of contact (adhesion or friction as the case may be) between individual [an organization's] experience/action and the social 
context" (Crouch and McKenzie 2006, p. 491). Further, garnering these key perspectives help to espouse the circumstantial nuances of negotiating societal contexts and societal trends that regulate the provincial rugby union sport sponsorship terrain as acts of agency (in what they do) and/or as responses to structure (in what they endure; Abbott 1992). As such, semi-structured interviews were conducted with the sponsorship managers or CEOs (depending on responsibilities) from the six purposively selected regional rugby unions. Potential respondents were initially identified from each organization's respective website, then emailed and invited to participate in the study. Representatives from all six regional rugby unions located within the chosen geographic area responded, which included five males and one female. Each respondent was provided with the research objectives, participant contribution expectations and confidentiality information. Participation in the study was voluntary. Once participation was confirmed and interview times and locations arranged, participants were asked a series of questions on a range of issues related to sponsorship for the organization, including: the sponsorship decision making processes, dependency on sponsorship, the prospective threat of a ban of alcohol sponsorship of sport, and the potential implications of increasing restrictive sponsorship legislation on the capabilities of organizations to deliver rugby at the regional level. Anonymity was offered to each respondent and their associated organization. Three interviews were conducted face-to-face, and the other three over the phone. Interviews ranged between 40 to $60 \mathrm{~min}$ in length. Interviews were audio-recorded and then transcribed verbatim. As a form of member checking (Amis 2005), individual transcripts were returned to each participant to verify that it was an accurate representation of what was discussed.

\subsection{Data Analysis}

Upon receiving transcript verification, transcripts were uploaded to NVivo12. A threestage data analysis process was adopted that incorporated manual open, axial and selective coding methods as advocated by Auerbach and Silverstein (2003), Bazeley (2013), and Gillham (2008). For example, the axial coding process identified specific tree nodes within the NVivo12 software, which were used to identify thematic findings. Following this process, interview transcripts were read and re-read for key words, phrases, or segments of texts that were manually highlighted and coded to new or recurring categories. Interviewee statements were categorized according to four emergent themes. Research findings are presented in the following section with quotes from participants indicating their gender and the rural/suburban/urban nature of their rugby union.

\section{Findings}

Four themes emerged from the data analysis: a lack of sponsorship options, an overreliance on alcohol industry sponsorship, rugby unions being socially responsible with their alcohol sponsorship and good community citizens, and the culturally ingrained and complex relationship between rugby and beer. 


\subsection{Lack of Sponsorship Options}

All of the participants commented on a lack of alternative sponsorship options. For some of the provincial rugby unions, their geographical location, size, and demographics delimited the diversity of sponsorship opportunities available to them. A participant from a smaller province identified that sponsorship in rugby is "very localized. Very localized. We can't go and get a national brand...it would be very hard" (P1, male, rural). In this context, he was describing the absence of big corporate and industrial partners in his region to approach for sponsorship funds. On the other hand, participants from rural rugby unions asserted that beer brand and brewery sponsorship in smaller regions comes easily (P1/P3), and even for larger, more urban unions "... at the end of the day money talks and beggars can't be choosers" (P2, male, urban). P2 further discussed the drudgery of finding sponsors, but admitted that if breweries were forthcoming with their willingness to sponsor rugby clubs then he was prepared to accept their funds without hesitation to diminish his task of "hunting and gathering" sponsors for his union.

Parallel to the broader discussion on the size of some provinces inhibiting sponsorship options, one participant clarified that the individual local rugby clubs (or teams) within a union would be the hardest hit with increased government-sanctioned sponsorship restrictions. He stated that, "We're limited in terms of the walls of our province. ... Many of our clubs have individual brewery or pub sponsor arrangements. That's where the impact would be felt if pressure filtered through. They rely a lot more on sponsorship" (P3, male, rural). Participants also agreed that a commitment of sponsorship replacement funding from the government would help to address their concerns about a potential ban of alcohol sponsorship of sport, because of a lack of alternatives. As one participant noted, "If you took away a club's brewery sponsorship there wouldn't be enough funding left. The government has got a very fine balance and it wouldn't take much to tip the scales" (P4, male, urban). He further suggested that greater restrictions on alcohol sponsorship of sport would have to be supplemented by government, "because they're the ones fighting the sponsorship in the first place... [but] they have a limited amount of available funding that they'll put into sponsorship" (P4, male, urban). Overall, the provision of rugby in communities and provinces is dependent on a sponsorship landscape that is finite, fragile, and at times difficult to forsake.

\subsection{Over-Reliance on Alcohol Industry Sponsorship}

All of the participants acknowledged that the amount of discussion and debate about alcohol sponsorship of sport presented through the findings of both governmentcommissioned reviews and the subsequent reporting through popular news outlets naturally incited a need for rugby unions to be able to respond to a potential alcohol sponsorship ban. Some participants were thankful that they had recently secured longterm alcohol sponsorship contracts, but admitted that in the event of a ban, the substantial cash (up to $\$ 1$ million in larger rugby unions) obtained from one alcohol sponsor may need to be acquired through several, smaller sponsorship agreements. As one participant stated, "We're quite lucky that our contract [with alcohol brewery] runs for a number of years...it is quite significant compared to others. ... We actually get a significant amount of cash. That's something that we'll probably see reduce. We'll be 
relying on many, many smaller sponsorship contracts to compete the portfolio as opposed to one or two bigger ones" (P2, male, urban). Given participants' previously noted apprehensions highlighting a lack of other, non-alcohol branded, sponsorship options, obtaining a greater number of smaller sponsorships may prove difficult for some unions.

Some participants expressed their confidence in the strength of their union's financial position, due to a lack of a complete reliance on alcohol sponsorship, compared to others. Regardless, these participants also acknowledged the risk, with one admitting that:

We have diversity in terms of where we source our revenue streams from... [but] we'll find ourselves in a bit of a pickle if legislation should be introduced overnight. ... We would be in trouble or at risk. A great deal of trouble. [But] we would still be in a far better place than a lot of other [smaller] rugby unions. (P2, male, urban)

While the financial risk was a major concern for all unions, there was consensus among participants that the size of the union and the province that it serves are compounding factors to understanding the extent to which a ban would effect a particular union.

Overall, participants identified a lack of clarity about potential sponsorship reforms yet noted that the consequences would be considerable. In particular, one participant discussed the dependence of sponsorship investment to the funding structures of rugby unions in New Zealand and identified that a ban of alcohol sponsorship of sport could act as an unwelcomed trigger to restructuring rugby in New Zealand altogether. He alleged that "Sponsorship issues could be the catalyst for reviewing the structure of the unions in due course. No one wants to go there. New Zealand Rugby doesn't" (P4, male, urban). In order to avoid such a catastrophe, participants claimed that their unions were not ignorant to the "national discussions that publicize concern regarding alcohol sponsorship" (P3, male, rural) and are, instead, strategizing about what might come, if anything, given the number of years this discussion has been occurring since the 2010 Law Commission report.

\subsection{Social Responsibility and Centrality to Community}

Several participants recognized the social and political context of their union's presence within their communities and, therefore, a need to promote themselves and their sponsors (including breweries and beer brands) in a responsible manner. For some unions, participants detailed their alcohol sponsorship as a combination of receiving cash, in-kind (field signage, etc.), and/or alcohol products. The in-kind sponsorship was cited as the element that creates the most imposition for a union or club and gives the illusion of being irresponsible if used in inappropriate contexts. As one participant recounted, "I have to be careful not to put [beer branded] goal post protectors on goalposts in fields with children's rugby" (P6, female, suburban). This participant aspired for their union to be regarded as an organization that is cognizant not to advertise alcohol brands at youth sport events or matches, wherein decreasing youth exposure to alcohol signage is an argument repeatedly used in favour of banning alcohol sponsorship of sport. Another participant shared this view and stated, "There's 
[beer branded] flags and goal post pads, and then the logos are on some of the gear. Most of it is targeted at the [elite] team, so over 18" (P5, male, suburban). Their justification claimed that most of their union's beer-branded in-kind objects are targeted at the more elite-level team whose players are 18 years and older (18 is the legal purchase age of alcohol in New Zealand), but potentially what is overlooked in his point are the youth fans of the over-18 team and the promotion of a naturalized connection of beer with rugby at the so-called 'coming of age'.

Moreover, these same two participants rationalized their age-appropriate alcohol promotion strategies by accentuating the accountability of their organizations to their communities: "We have to ensure we are responsible hosts" (P6, female, suburban), and "We need to make sure we're acting as a good citizen" (P5, male, suburban). The need to be viewed favourably by the community suggests ideas of moral judgement in the promotion of alcohol to youth. Aligning with these sentiments is another participant's claim about the centrality of the rugby union and local clubs in some rural communities:

I wouldn't want [alcohol sponsorship] to disappear. I think it's telling a community what they can and can't do. Our community very much centres around the sports club. You only have to go on today's [newspaper] where it states that the sports club is a great way for decreasing depression out in the rural areas. That's what we are, a rural community. If you take away the ability for people to come together once a week, play some sport and have a beer then you're really manipulating society. (P1, male, rural)

This participant, like others, felt that the funding from alcohol sponsorships enabled the provision of rugby in his local community, which contributes to better collective mental health. Challenges that influence the provision of sport in rural areas could have ripple effects on other health- and social-related ills.

\subsection{Culturally Ingrained and Complex Relationship between Rugby and Beer}

Many of the participants noted the link between beer and rugby in New Zealand society. One participant specifically commented on the embedded nature of the two: "Rugby and beer - there's that perception that they go hand in hand" (P6, female, suburban). This link is not remiss when garnering sponsorship for rugby. In particular, P5 (male, suburban) explicitly stated that no other industry is as extensive on a national scale as beer: "There are 26 [rugby] unions in New Zealand. I'm pretty sure in saying that every single one of them has a brewery sponsor. ... I don't see something in relation to rugby that is a product that is in every province strongly enough that could fill that void" if alcohol sponsorship of sport was banned. In a sense, the strongholds of beer and of rugby in each province are recognized as key assurances of New Zealand civic life.

P5 further described the complexity of brewery sponsorship of rugby in New Zealand as: "multi-tiered. I've got nine local clubs that have their own brewery sponsorship agreements. Then there's the [professional provincial franchise team] which we're part owners and they have a [different] brewery. Then there's the All Blacks and their brewery sponsor." This comment signifies the suturing of beer 
sponsorship throughout the rugby system. These rugby-beer sponsorship intricacies suggest that a proposed ban of alcohol sponsorship of sport would need to address all levels of sport, not singularly target the grassroots level nor the professional/elite level.

Overall participants were indifferent about the association of the alcohol industry with rugby. In particular, one participant stated: "Our stance is that none of these sponsors are illegal. They run perfectly legal businesses. There's nothing stopping people walking into these organizations off the street. When it comes to alcohol...it's everything in moderation" (P2, male, urban). Here, the participant highlights a general acceptance of breweries as lawful industries and the belief that the public are free to support these organizations independently of sport, appears to dissolve any misgivings of a relationship between alcohol companies and rugby. Moreover, P2's perception emphasizes moderation, which hints at the notion of self-regulation as a control mechanism and aligns with current industry policy practices in New Zealand.

\section{Discussion}

From these conversations, a number of greater considerations arise. First, rugby unions and local clubs may not have the capacity (or desire) for sponsorship change. Despite the paradoxical relationship between alcohol and sport, alcohol sponsorship serves as a primary revenue stream for many of these sport organizations, that may not be able to survive without it. The presence of such an impactful single sponsor has created a dependence among clubs on one funding source (cf. Filo et al. 2015; Pfeffer and Salancik 2003) and, more specifically, a dependence on the alcohol industry to support sport and its various health and community outcomes. As such, the risks associated with the loss of this critical resource are even greater, especially considering the few alternatives available to fill the void that a ban on alcohol sponsorship would introduce. As participants noted, even those organizations with somewhat strong revenue diversification view this as a significant risk to their survival. This is likely due to the financial uncertainty this would cause and the subsequent strain on the organization's overall capacity to adapt to this change. Removing alcohol sponsorship would require rugby unions and local clubs to draw on their human resources, develop strategic sponsorship plans, and expand their networks in order to secure additional, smaller sponsors to fill that void (e.g., Misener and Doherty 2014; Wicker and Breuer 2014). It was apparent, among the participants in this study, that there is a profound fear of the toll that this would have on their clubs and a general lack of confidence in their club's ability to survive this change. The fear here is that when "demand for change greatly exceeds capacity, the organization [may] catapult into dysfunction" (Conner and Hoopes 1997 , p. 17). From the local to national level, rugby unions and local clubs in New Zealand may not have the existing capacity to withstand the demands for change introduced by a ban on alcohol sponsorship (cf. Millar and Doherty 2020). The dependence on resources acquired through alcohol sponsorship, combined with the limited government funding for sport in New Zealand (Cordery et al. 2013), place rugby unions and local clubs in a highly vulnerable position should a ban be instituted.

Second, as membership-based organizations, regional rugby unions must balance their accountabilities to all of their stakeholders, servicing the government, sponsors, communities, and the public. Regional rugby unions and local clubs (as well as other 
sport organizations) provide a social good for their communities with the funding currently available to them, including alcohol industry sponsorship (e.g., Sabbe et al. 2020; Spaaij 2013). They also need to negotiate the business interests of the organization with the fact that they play an important role in fostering community well-being (Edwards 2015; Trussell 2020). These perhaps conflicting priorities highlight the complexity of this issue. As participants noted, if the government ratified a ban on alcohol sponsorship, this would essentially take away their ability to bring people together around sport and would set a concerning precedent around governing what communities can and cannot do in order to support the community-minded interests of sport organizations. This was particularly evident among participants from rural communities, highlighting a position of resistance to dominant (urban) ideals around sport and, more specifically, the role of sport in building community well-being. Notably, the notion of a ban on alcohol sponsorship was viewed as a perceived threat to a way of life at the community level; one that would drastically impede the roles of rugby unions and locals clubs to serve as central pillars in their communities and that would significantly hinder their ability to facilitate community relations among citizens and further community development (Robertson et al. 2018). Without the local rugby club, many municipalities would lose a key means for civic engagement, especially in rural areas. The findings presented here further support Sport New Zealand's submission to the Ministerial Forum on Alcohol Advertising and Sponsorship that suggested a restriction on alcohol sponsorship would endanger the existence of community sports clubs and events (Ministry of Health 2014a). Moreover, some participants believed that other issues in their communities were of greater social importance than the alcohol sponsorship debate. For example, one participant noted that their region had the highest rates of kids not taking a lunch to school and their rugby union viewed its purpose to help with that community issue. Evidently, this participant felt that the role of their rugby union in serving the community expanded beyond sport provision and far outweighed concerns regarding the appropriateness of alcohol sponsorship. Yet, without alcohol sponsorship the ability of the rugby union to fulfil these types of community roles becomes jeopardized.

Third, blanket restrictions on alcohol sponsorship of sport cannot be a one-size-fitsall approach. There are essential regional variances to consider based on the population and demographics of a province/region (e.g., socio-economic differences, number of people living in the region, the nature of people's work and occupations, proximity to other settlements for competition), but also size of the organization (e.g., number employees, volunteers, members/participants). Smaller, more rural, rugby unions and clubs will be at the greatest financial risk if a ban on alcohol sponsorship of sport is enforced. This is due to a perceived lack of available non-alcohol sponsorship options and a need for more resources to seek and secure non-alcohol sponsorship. These factors may further accentuate a urban-rural divide in the New Zealand sport context (Ryan 2008), where the resource-rich, urban unions appear richer (because they have a greater number and diversity of industries and companies to approach for sponsorship in their region as well as more people working in the rugby union to be tasked with approaching and obtaining sponsorship), and the resource-poor, rural unions become threatened. The potential abrogation of these community-based organizations due to limited non-alcohol funding sources may impose adverse effects on civic identity and community life in rural regions (PS Services 2010) that are also contending with 
impacts of urbanization (Brown et al. 2019), including the migration of talented rugby players to larger cities (Ryan 2008).

Relatedly, there is potential for different sports to experience a ban of alcohol sponsorship differently. For example, basketball or soccer may demonstrate greater success in transitioning away from alcohol sponsors than rugby. This is due to the normalized, cultural link between beer, men's rugby, and New Zealandness (cf. Gee 2013; Gee et al. 2018). Challenges to this triad - in the form of stricter regulations on alcohol sponsorship of men's rugby - present a threat (however real or imaginary) to a range of gendered, sporting, and nationalistic norms, values, cultural customs and protocols, and institutions that otherwise define a way of life that has gone unquestioned for decades. Historical partnerships between, and accepted (and expected) gendered manifestations through, beer and rugby have contributed to the ways in which alcohol sponsorship of rugby in New Zealand is normalized. And, while participants have shared their views on the risks of a ban on alcohol sponsorship, it is worth noting that they may also hold unspoken preferences for beer sponsors as constituting a cultural fit with men's rugby. Given the genders of the participants (i.e., five males and one female), we acknowledge that their views may be consciously (or unconsciously) influenced by their own cultural/alcohol/sporting experiences and understandings, and are expressive of a predominantly male 'beer and rugby' culture under threat. Disentangling this tightly knit relationship will likely require an increased evidence base that extends beyond examining macro-level changes in sponsorship regimes to include an intricate understanding of the micro-level nuances between beer and rugby, and the importance of rugby to New Zealand national identity (Phillips 1996; Scherer and Jackson 2010, 2013).

\section{Conclusion}

This study examined the perceptions of and challenges for regional rugby unions to navigate a potential ban of alcohol sponsorship of sport. The findings revealed a range of themes that highlight the social and cultural importance of, as well as the financial dependence on, alcohol sponsorship. As such, this study represents a starting point to understanding the potential implications of a ban of alcohol industry funding to sport and emphasizes a need to be cognizant of the extent to which a ban is laced with a 'ripple effect' on the lived realities for communities and civic engagement. That is, although it is hoped that a ban on alcohol sponsorship of sport would serve as an abrupt stop to the paradoxical association between alcohol and sport, the financial influence of such a decision could have catastrophic results that reach further afield. This paper offers an interesting case study of how structural forces (political and business interests) exercise power and influence on local sporting practices and how these influences are resisted and incorporated among community-based sporting organizations. At the same time, it can be read as much as a case study on public health or social policy, or as an enquiry into the financial pressures faced by local sporting organizations.

Grounded in the New Zealand rugby context, these findings may not be generalizable to other sports within New Zealand or to sport organizations outside of New Zealand. Yet, debates on alcohol sponsorship of sport reverberate globally. As such, this paper addresses issues with potentially broad geographical relevance including, for 
example, any nation or region where sport is supported through alcohol-related sponsorship, or where choices for community funding and/or partnerships are dependent upon limited commercial sources. Upon a cursory view, this appears to (potentially) cover many sports in many countries. Therefore, research that investigates different sporting and national environments may unearth further insights to help frame the terms of these debates. To this end, there is a need to be mindful of other national alcohol policy contexts where alcohol sponsorship of sport is banned (e.g., the Loi Évin in France), and the extent to which these regulatory practices are promoted as successful blueprints for others to follow (Casswell 2014; Kypri et al. 2009). In the specific case of France, since 1991 Loi Évin (or Evin's Law) has prohibited alcohol sponsorship of cultural and sporting events and teams in an effort to help reduce alcohol consumption (Rigaud \& Craplet, 2004). However, sport organizations continue to seek and exploit several loopholes in the French law (Bodet et al. 2020), and the French government has received recent proposals to relax the law to assuage financial pressures for sports clubs amidst the COVID-19 pandemic (Huffington Post 2020).

As sport organizations continue to face a number challenges with regard to increased facility costs, demands from members, and an overall trend towards the commercialization of community sport, diversifying sponsorship portfolios (irrespective of a ban of alcohol sponsorship) may prove beneficial to ensure greater financial stability and less dependence on one funding source (Bradbury et al. 2020). Future research that investigates existing capacity for change within sport organizations would offer insights into how these clubs may adapt or react in order to survive such a drastic change to their funding model. Ultimately, the sport and alcohol sponsorship landscape in New Zealand remains complex with a number of considerations beyond whether or not to establish and implement new laws. It is about developing viable, fit-for-purpose, coopted social and cultural change regarding alcohol sponsorship of sport that meets the needs of all involved in sport: providers, investors, participants, and consumers. Perhaps when government reviews occur they incite elements of a crisis or panic, but without formalized laws to stimulate and mandate change, business as usual resumes.

\section{Authors' Contributions Not applicable.}

Funding No funds, grants, or other support was received.

Data Availability Interview transcripts are not publicly available.

Compliance with Ethical Standards All authors certify that they have no affiliations with or involvement in any organization or entity with any financial interest or non-financial interest in the subject matter or materials discussed in this manuscript.

Conflicts of Interest/Competing Interests Not applicable.

Informed Consent Informed consent was obtained from all individual participants included in the study.

Ethical Approval Approval was obtained from the ethics committee of Massey University for Low Risk Notification. The procedures used in this study adhere to the tenets of the Declaration of Helsinki.

Code Availability Transcript coding processes are not publicly available. 


\section{References}

Abbott, A. (1992). What do cases do? Some notes on activity in social analysis. In C. C. Ragin \& H. S. Becker (Eds.), What is a case? Exploring the foundations of social inquiry (pp. 53-82). Cambridge: Cambridge University Press.

Amis, J. (2005). Interviewing for case study research. In D. Andrew, P. Pedersen, \& C. McEvoy (Eds.), Research methods and design in sport management (p. 101). New York: Routledge.

Anthony (2016). Alcohol advertising and sponsorship in sport to be addressed by government. Stuff.co.nz. Retrieved from: https:/www.stuff.co.nz/business/industries/81166101/alcohol-advertising-andsponsorship-in-sport-to-be-addressed-by-government

Auerbach, C., \& Silverstein, L. (2003). Qualitative data: An introduction to coding and analysis. New York: New York University Press.

Babor, T., Caetano, R., Casswell, S., et al. (2010). Alcohol: No ordinary commodity. Oxford: Oxford Uni Press.

Batty, R. J., Cuskelly, G., \& Toohey, K. (2016). Community sport events and CSR sponsorship: examining the impacts of a public health agenda. Journal of Sport and Social Issues, 40(6), 545-564.

Bazeley, P. (2013). Qualitative data analysis: Practical strategies. London: Sage Publications.

Bodet, G., Routier, G., \& Fuchs, S. (2020). Alcohol and sport in France: An unsettled field. In S. Gee (Ed.), Sport, alcohol and social inquiry: A global cocktail. Bingley: Emerald Publishing Limited.

Bradbury, T., Mitchell, R., \& Thorn, K. (2020). Moving forward: Business model solutions for amateur sport clubs. Managing Sport and Leisure. https://doi.org/10.1080/23750472.2020.1734479.

Braun, V., \& Clarke, V. (2006). Using thematic analysis in psychology. Qualitative Research in Psychology, 3(2), 77-101.

Brown, M., Kaye-Blake, B., \& Payne, P. (2019). Heartland strong: How rural New Zealand can change and thrive. Palmerston North: Massey University Press.

Bujdosó, Z., \& Szücs, C. (2012). Beer tourism-from theory to practice. Academica Turistica, 5(1), $103-111$.

Carter, M., Signal, L., Edwards, R., Hoek, J., \& Maher, A. (2013). Food, fizzy and football: promoting unhealthy food and beverages through sport - a New Zealand case study. BMC Public Health, 13(126), $1-7$.

Casswell, S. (2014). Profits or people? The informative case of alcohol marketing. New Zealand Medical Journal, 127(1406), 87-92.

Cody, K., \& Jackson, S. (2016). The contested terrain of alcohol sponsorship of sport in New Zealand. International Review for the Sociology of Sport, 51(4), 375-393.

Collins, T., \& Vamplew, W. (2002). Mud, sweat and beers. London: Bloomsbury.

Conner, D. R., \& Hoopes, L. L. (1997). Elements of human due diligence: supporting the nimble organization. Consulting Psychology Journal: Practice and Research, 49(1), 17-24. https://doi.org/10.1037/10614087.49.1.17.

Cordery, C. J., Sim, D., \& Baskerville, R. F. (2013). Three models, one goal: assessing financial vulnerability in New Zealand amateur sport clubs. Sport Management Review, 16, 186-199.

Creswell, J. (2009). Editorial: mapping the field of mixed methods research. Journal of Mixed Methods Research, 3(2), 95-108.

Crompton, J. L. (2014). Potential negative outcomes from sponsorship for a sport property. Managing Leisure, 19(6), 420-441.

Crouch, M., \& McKenzie, H. (2006). The logic of small samples in interview-based qualitative research. Social Science Information, 45(4), 483-499.

Doherty, A., \& Cuskelly, G. (2020). Organizational capacity and performance of community sport clubs. Journal of Sport Management, 34, 240-259.

Doherty, A., Misener, K., \& Cuskelly, G. (2014). Toward a multidimensional framework of capacity in community sport clubs. Nonprofit and Voluntary Sector Quarterly, 43(2), 124S-142S.

Donovan, T., Bowler, S., Hanneman, R., \& Karp, J. (2004). Social groups, sport and political engagement in New Zealand. Australian Journal of Political Science, 39(2), 405-419.

Duarte Alonso, A., Alexander, N., \& O’Brien, S. (2018). "Every brew is a challenge and every glass of a good beer is an achievement": home brewing and serious leisure. Leisure/Loisir, 42(1), 93-113.

Dunning, E. (1986). Sport as a male preserve: notes on the social sources of masculine identity and its transformations. Theory, Culture \& Society, 3(1), 79-90.

Edwards, M. B. (2015). The role of sport in community capacity building: an examination of sport for development research and practice. Sport Management Review, 18, 6-19.

Edwards, A., \& Skinner, J. (2009). Qualitative research in sport management. Oxford: Elsevier. 
Eime, R. M., Young, J. A., Harvey, J. T., Charity, M. J., \& Payne, W. R. (2013). A systematic review of the psychological and social benefits of participation in sport for children and adolescents: informing development of a conceptual model of health through sport. International Journal of Behavioral Nutrition and Physical Activity, 10, 1-21.

Eisenhardt, K., \& Graebner, M. (2007). Theory building from cases: opportunities and challenges. Academy of Management Journal, 50(1), 25-32.

Filo, K., Cuskelly, G., \& Wicker, P. (2015). Resource utilization and power relations of community sport clubs in the aftermath of natural disasters. Sport Management Review, 18, 555-569.

Gee, S. (2013). The culture of alcohol sponsorship during the 2011 Rugby World Cup: an (auto) ethnographic and (con) textual analysis. Sport in Society, 16(7), 912-930.

Gee, S. (2020). Introduction. In S. Gee (Ed.), Sport, alcohol and social inquiry: A global cocktail. Bingley: Emerald Publishing Limited.

Gee, S., \& Jackson, S. J. (2010). The southern man city as cultural place and Speight's space: locating the masculinity-sport-beer 'holy trinity' in New Zealand. Sport in Society, 13(10), 1516-1531.

Gee, S., \& Jackson, S. J. (2012). Leisure corporations, beer brand culture, and the crisis of masculinity: the Speight's 'southern man' advertising campaign. Leisure Studies, 31(1), 83-102.

Gee, S., \& Jackson, S. J. (2017). Sport, promotional culture, and the contemporary crisis of masculinity. London: Palgrave Macmillan.

Gee, S., Jackson, S. J., \& Sam, M. (2016). Carnivalesque culture and alcohol promotion and consumption at an annual international sports event in New Zealand. International Review for the Sociology of Sport, 51(3), 265-283.

Gee, S., Thompson, A. J., \& Batty, R. J. (2018). Rules of engagement: sport sponsorship, anti-ambush marketing legislation, and alcohol images during the 2011 Rugby World Cup. Journal of Global Sport Management, 3(3), 266-283.

Gillham, B. (2008). Observation techniques - Structured and unstructured. London: Continuum.

Grainger, A., Falcous, M., \& Newman, J. (2012). Postcolonial anxieties and the browning of New Zealand Rugby. The Contemporary Pacific, 24(2), 267-296.

Huffington Post. (2020). Un rapport du Sénat propose d'assouplir la loi Évin pour renflouer les clubs après le Covid. Huffington Post. Retrieved 25 June 2020 from: https:/www.huffingtonpost.fr/entry/un-rapportdu-senat-propose-dassouplir-la-loi-evin-pour-renflouer-les-clubs-apres-le-covid_fr_ 5eebf971c5b6e85eae2db430

Jackson, S. J. (2014). Globalisation, corporate nationalism and masculinity in Canada: sport, Molson beer advertising and consumer citizenship. Sport in Society, 17(7), 901-916.

Johnson, W.O. (1988). Sports and suds. Sports Illustrated, 8 August, 68-82.

Jones, S. C. (2010). When does alcohol sponsorship of sport become sports sponsorship of alcohol? A case study of developments in sport in Australia. International Journal of Sports Marketing and Sponsorship, 11(3), 67-78.

Jones, G. J., Edwards, M. B., Bocarro, J. B., Bunds, K. S., \& Smith, J. W. (2018). Leveraging community sport organizations to promote community capacity: strategic outcomes, challenges, and theoretical considerations. Sport Management Review, 21, 279-292.

Kay, T., \& Bradbury, S. (2009). Youth sport volunteering: developing social capital? Sport, Education and Society, 14(1), 121-140.

Kypri, K., O’Brien, K., \& Miller, P. (2009). Time for precautionary action on alcohol industry funding of sporting bodies. Addiction, 104(12), 1949-1950.

Law Commission. (2010). Alcohol in our lives: Curbing the harm. A report on the review of the regulatory framework for the sale and supply of liquor. Report 114. Wellington: New Zealand Law Commission.

Pringle, R., \& Markula, P. (2005). No pain is sane after all: A Foucauldian analysis of masculinities and men's experiences in rugby. Sociology of Sport Journal, 22, 472-497.

Mair, H. (2009). Club life: third place and shared leisure in rural Canada. Leisure Sciences, 31(5), 450-465.

McDaniel, S. R., \& Mason, D. (1999). An exploratory study of influences on public opinion towards alcohol and tobacco sponsorship of sporting events. Journal of Services Marketing, 13(6), 481-499.

Meenaghan, J. A. (1983). Commercial sponsorship. European Journal of Marketing, 17(7), 5-73.

Merriam, S. (2009). Qualitative research: A guide to design and implementation. San Francisco: Jossey-Bass.

Millar, P., \& Doherty, A. (2020). Readiness for capacity building in community sport organizations. Managing Sport and Leisure. https://doi.org/10.1080/23750472.2020.1763830.

Ministry of Health. (2014a). Analysis of submissions to the ministerial forum on alcohol advertising and sponsorship. Wellington, NZ: Allen+Clarke. https://www.health.govt.nz/publication/summarysubmissions-ministerial-forum-alcohol-advertising-and-sponsorship 
Ministry of Health. (2014b). Recommendations on alcohol advertising and sponsorship. Ministerial Forum on Alcohol Advertising and Sponsorship. https:/www.health.govt.nz/system/files/documents/publications/ ministerial-forum-on-alcohol-advertising-and-sponsorship-recommendations-on-alcohol-advertising-andsponsorship-dec14.pdf

Misener, K., \& Doherty, A. (2014). In support of sport: examining the relationship between community sport organizations and sponsors. Sport Management Review, 17, 493-506.

Munro, G. (2000). Challenging the culture of sport and alcohol. International Journal of Drug Policy, 11(3), 199-202.

Nauright, J., \& Chandler, T. (1996). Making men: Rugby and masculine identity. London: Frank Cass.

New Zealand Rugby (2019). New Zealand Rugby annual report 2018. Retrieved from http://files.allblacks. com/publications/2018-NZR-Annual-Report.pdf

Nichols, G., Taylor, P., Barrett, D., \& Jeanes, R. (2014). Youth sport volunteers in England: a paradox between reducing the state and promoting a big society. Sport Management Review, 17(3), 337-346.

Nicholson, M., Brown, K., \& Hoye, R. (2013). Sport's social provision. Sport Management Review, 16, 148160.

O’Brien, K. S., Ali, A., Cotter, J. D., O'shea, R. P., \& Stannard, S. (2007). Hazardous drinking in New Zealand sportspeople: level of sporting participation and drinking motives. Alcohol \& Alcoholism, 42(4), 376-382.

O'Brien, K. S., \& Kypri, K. (2008). Alcohol industry sponsorship and hazardous drinking among sportspeople. Addiction, 103(12), 1961-1966.

Palinkas, L. A., Horwitz, S. M., Green, C. A., Wisdom, J. P., Duan, N., \& Hoagwood, K. (2015). Purposeful sampling for qualitative data collection and analysis in mixed method implementation research. Administration and Policy in Mental Health, 42(5), 533-544.

Palmer, C. (2011). Key themes and research agendas in the sport-alcohol nexus. Journal of Sport \& Social Issues, 35(2), 168-185.

Pfeffer, J., \& Salancik, G. R. (2003). The external control of organizations: A resource dependence perspective. Stanford University Press.

Phillips, J. (1996). The hard man: Rugby and the formation of male identity in New Zealand. In J. Nauright \& T. J. L. Chandler (Eds.), Making men: Rugby and masculine identity (pp. 70-90). London: Frank Cass.

Pringle, R., \& Markula, P. (2005). No pain is sane after all: A Foucauldian analysis of masculinities and men's rugby experiences of fear, pain, and pleasure. Sociology of Sport Journal, 22(4), 472-497.

PS Services (2010). Alcohol and sport: What is the nature of the relationship and is there a problem? A scoping study prepared for SPARC Ihi Aotearoa. Available at: http:/www.sparc.org.nz/Documents/ Research/Report-Nov-AlcoholandSport.pdf.

Rigaud, A., \& M.Craplet. (2004). The Loi Evin - A French Exception. The Globe, 1(2), 33-6.

Robertson, J., Eime, R., \& Westerneek, H. (2018). Community sport clubs: are they only about playing sport, or do they have broader health promotion and social responsibilities? Annals of Leisure Research, 22(2), 215-232.

Rojek, C. (2010). The labour of leisure: The culture of free time. London: Sage.

Rowe, D., \& Gilmour, C. (2009). Lubrication and domination: Beer, sport, masculinity, and the Australian gender order. In L. Wenner \& S. Jackson (Eds.), Sport, beer, and gender: Promotional culture and contemporary social life (pp. 203-221). Zurich: Peter Lang Publishers.

Ryan, G. (2008). Theatregoers in the heartland: New Zealand rugby and the contradictions of professionalism. In G. Ryan (Ed.), The changing face of Rugby: The Union game and professionalism since 1995 (pp. 4162). Angerton Gardens, Newcastle: Cambridge Scholars Publishing.

Sabbe, S., Bradt, L., Spaaij, R., \& Roose, R. (2020). Community sport and social cohesion: in search of the practical understanding of community sport practitioners in Flanders. Community Development Journal, 55(2), 258-276.

Sam, M. P. (2009). The public management of sport: wicked problems, challenges and dilemmas. Public Management Review, 11(4), 499-514.

Scherer, J., \& Jackson, S. (2010). Globalization, sport and corporate nationalism: The new cultural economy of the New Zealand all blacks. Switzerland: Peter Lang.

Scherer, J., \& Jackson, S. (2013). The contested terrain of the New Zealand all blacks: Rugby, commerce, and cultural politics in the age of globalization. Oxford: Peter Lang.

Scherer, J., Falcous, M., \& Jackson, S. (2008). The media sports cultural complex: local global disjuncture in New Zealand/Aotearoa. Journal of Sport and Social Issues, 32(1), 48-71.

Sharpe, E. K. (2006). Resources at the grassroots of recreation: organizational capacity and quality of experience in a community sport organization. Leisure Sciences, 28(4), 385-401. 
Shaw, S., \& Hoeber, L. (2016). Unclipping your wings: ways forward in qualitative research in sport management. Sport Management Review, 19(3), 255-265.

Skegg, D. (2019). The health of the people. Wellington: Bridget Williams Books.

Spaaij, R. (2013). Sport, social cohesion and community building: Managing the nexus. In P. Leisink, P. Boselie, M. van Bottenburg, \& D. M. Hosking (Eds.), Managing social issues: A public values perspective (pp. 107-125). Cheltenham: Edward Elgar Publishing Limited.

Thurnell-Read, T. (2016). "Real ale" enthusiasts, serious leisure and the costs of getting "too serious" about beer. Leisure Sciences, 38(1), 68-84.

Tonts, M. (2005). Competitive sport and social capital in rural Australia. Journal of Rural Studies, 21, 137149.

Trussell, D. E. (2020). Building inclusive communities in youth sport for lesbian-parented families. Journal of Sport Management, 34, 367-377.

Waardenburg, M. (2016). Which wider social roles? An analysis of social roles ascribed to voluntary sport clubs. European Journal for Sport and Society, 13(1), 38-54.

Warner, S., Dixon, M. A., \& Chalip, L. (2012). The impact of formal versus informal sport: mapping the differences in sense of community. Journal of Community Psychology, 40(8), 983-1003.

Warner, S., Kerwin, S., \& Walker, M. (2013). Examining sense of community in sport: developing the multidimensional 'SCS' scale. Journal of Sport Management, 27, 349-362.

Wendel, M. L., Burdine, J. N., McLeroy, K. R., Alaniz, A., Norton, B., \& Felix, M. R. (2009). Community capacity: Theory and application. In R. DiClemente, R. Crosby, \& M. C. Kegler (Eds.), Emerging theories in health promotion practice and research (2nd ed., pp. 277-302). San Francisco: Jossey-Bass Wiley Publishers.

Wenner, L. A. (1991). One part alcohol, one part sport, one part dirt, stir gently: Beer commercials and television sports. In L. R. V. Berg \& L. A. Wenner (Eds.), Television criticism: Approaches and applications (pp. 388-407). Addison-Wesley.

Wenner, L., \& Jackson, S. J. (2009). Sport, beer, and gender. Zurich: Peter Lang Publishers.

Wicker, P., \& Breuer, C. (2014). Exploring the organizational capacity and organizational problems of disability sport clubs in Germany using matched pairs analysis. Sport Management Review, 17, $23-34$.

World Health Organization. (2014). Global status report on alcohol and health 2014. Geneva: World Health Organization.

Yin, R. K. (2012). Case study methods. In H. Cooper, P. M. Camic, D. L. Long, A. T. Panter, D. Rindskopf, \& K. J. Sher (Eds.), APA handbooks in psychology ${ }^{\circledR}$. APA handbook of research methods in psychology, Vol. 2. Research designs: Quantitative, qualitative, neuropsychological, and biological (pp. 141-155). American Psychological Association. https://doi.org/10.1037/13620-009.

Publisher's Note Springer Nature remains neutral with regard to jurisdictional claims in published maps and institutional affiliations. 